Artigo Original

\title{
O sistema de partida em corridas de velocidade do atletismo
}

\author{
Guy Ginciene \\ Sara Quenzer Matthiesen \\ Departamento de Educação Física e Grupo de Estudos Pedagógicos e Pesquisa em \\ Atletismo (GEPPA), IB/UNESP - Universidade Estadual Paulista, Rio Claro, SP, Brasil
}

\begin{abstract}
Resumo: Não é difícil observar a importância das corridas de velocidade para o cenário esportivo mundial. Entretanto, do stádion, disputado pelos gregos nos Jogos Olímpicos da Grécia Antiga, aos atuais 100 metros rasos, foram várias as modificações. Não por outro motivo, o objetivo dessa pesquisa foi registrar as modificações que ocorreram no sistema de partida das corridas de velocidade ao longo dos tempos. Essa pesquisa teórica, caracterizada como uma pesquisa bibliográfica, concentrou-se na coleta de dados provenientes de livros, artigos, imagens e websites relacionados aos 100 metros rasos. Dentre as modificações identificadas merecem destaque as que ocorreram no sistema de partida e que incluem o bloco de partida utilizado pelos atletas na atualidade, sem o qual, talvez, não se tivesse chegado ao incrível recorde mundial dos 100 metros rasos de 9s58.
\end{abstract}

Palavras-chave: Atletismo. História. Corrida.

\section{The starting system in speed racing of track and field}

Abstract: It is not difficult to realize the importance of speed racing to the world sports scene. However, from the stádion, disputed by the Greeks of the Olympic Games of Ancient Greece, to the current 100 meters dash, there were a lot of modifications. For no other reason, the objective of this research was to record the changes that occurred in the starting system from speed racing over time. This theoretical research, characterized as a literature search, focused on collecting data related to the 100 meter dash from books, articles, pictures and websites. Among the changes identified the ones that occurred with the starting system, which include the starting block used by athletes today deserve to be highlighted. Without that, perhaps, the incredible world record of 100 meters dash of $9 s 58$ would not have been achieved.

Keywords: Track and field. History. Race.

\section{Introdução}

Não é difícil observar a importância das corridas de velocidade, em especial, dos 100 metros rasos, para o cenário esportivo mundial. Entretanto, se observarmos as modificações que ocorreram nesta prova ao longo dos tempos, verificaremos que pouco as conhecemos. Por exemplo: desde quando as corridas de velocidade são disputadas em competições esportivas? Por que se utiliza a saída baixa? Desde quando essa é uma regra obrigatória de todas as corridas até e inclusive 400 metros? Quem foram os primeiros atletas a realizá-la?

Recorrendo a registros esparsos existentes na bibliografia da área, observamos que as corridas de velocidade fazem parte de competições esportivas, como os Jogos Olímpicos, desde sua primeira edição, em 776 a. C., na Grécia Antiga. Conhecida como stádion, os gregos, naquela época, disputavam essa corrida de velocidade numa reta de 192,27 metros. Do stádion aos atuais 100 metros rasos - disputados desde os I
Jogos Olímpicos da Era Moderna, em 1896 muitas coisas mudaram, dentre as quais merece destaque o sistema de partida da corrida propriamente dita, objeto de investigação dessa pesquisa.

\section{Objetivo}

Registrar, de forma didática, as modificações que ocorreram no sistema de partida das corridas de velocidade, desde o stádion, disputado nos Jogos Olímpicos da Grécia Antiga até os 100 metros rasos disputados na atualidade, contribuindo para o seu ensino em aulas de Educação Física.

\section{Metodologia}

Essa pesquisa teórica, caracterizada como uma pesquisa bibliográfica com fins didáticos, concentrou-se na coleta de dados provenientes de livros, artigos, imagens e websites relacionados às corridas de velocidade desde a Grécia Antiga até os dias atuais. 
Nesse processo de registro dos dados pertinentes às modificações que ocorreram no sistema de partida das corridas de velocidade, verificamos o quanto são restritas e, muitas vezes, desencontradas, as informações sobre o assunto exigindo, por parte do pesquisador, um confronto entre elas. Não à toa, orientamo-nos pelas informações esparsas presentes na bibliografia da área e nos detalhes observados nas imagens de diferentes épocas para registrar, de forma didática, esse percurso, cujo desenvolvimento não tem sido alvo constante de pesquisas acadêmicas, apesar da importância que a corrida de velocidade, em especial dos 100 metros rasos, assume no cenário esportivo de diferentes épocas. Afinal, como bem observou Matthiesen (2010) com base em pesquisa realizada por Faganello (2008), a história do atletismo, na maioria das vezes, se restringe a breves introduções em livros voltados aos ensinamentos técnicos, normativos ou de treinamento, sem que haja um aprofundamento acerca das modificações que ocorreram em cada uma de suas provas ao longo dos anos.

\section{Resultados}

Dentre as várias modificações que ocorreram nas corridas de velocidade ao longo dos tempos, vale observarmos os sistemas de partida utilizados na prova do stádion nos Jogos Olímpicos da Grécia Antiga e o utilizado na prova dos 100 metros rasos, nessa mesma competição na atualidade, para constatarmos que são inúmeras as diferenças que poderiam ser abordadas, sob o ponto de vista didático, em aulas de Educação Física. Por exemplo, se, atualmente, a saída baixa, com bloco de partida, é um dos elementos previstos pelas regras oficiais para a partida dos 100 metros rasos, é preciso dizer que foi longo o percurso e várias as modificações que fazem dessa uma obrigatoriedade entre as corridas de velocidade.

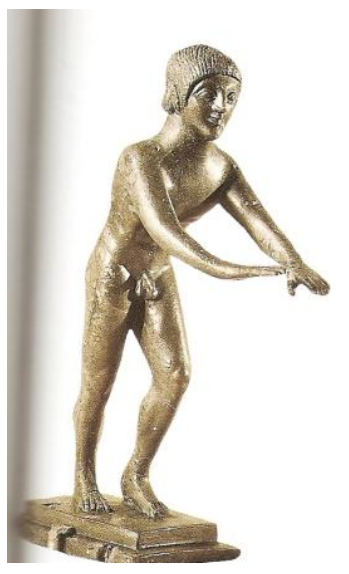

Figura 1- Momento da partida representado pela estatueta de bronze (ANDRONICOS et al, 2004, p. 177).

Não é difícil observar que na Grécia Antiga não havia bloco de partida ou a saída baixa em corridas de velocidade. Naquela época, os corredores largavam em pé, com os dedos apoiados em sulcos existentes na linha de partida - conhecida como balbídes - enquanto que os braços, segundo Andronicos et al (2004), ficavam à frente do corpo com as palmas das mãos voltadas para baixo (figura 1).

Complexo e bem diferente do atual, o sistema de partida naquela época era estruturado no formato de um triângulo, conforme podemos observar na figura 2.

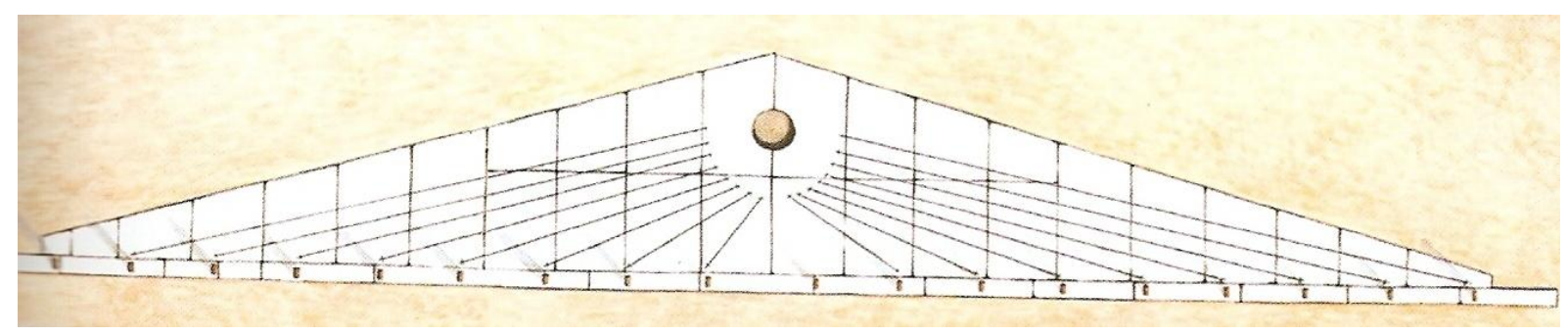

Figura 2- Sistema de partida da Grécia Antiga (

Conhecido como hýsplex esse sistema tinha um "operador de largada" - ou aphétes -, que hoje corresponderia ao árbitro de partida, posicionado atrás dos corredores a fim de comandar a partida, assim descrita por Andronicos et al (2004):
[...] havia barras móveis de madeira que permaneciam em posição horizontal sobre as estacas verticais, as quais separavam as posições dos corredores, que ficavam atrás dessas barras. Estas estavam conectadas a fios que passavam através das estacas verticais, desciam até a sua base e passavam através dos sulcos e dos grampos até chegarem ao 
aphétes, o operador da linha de partida, que segurava todos os fios juntos (p. 178).

Embora não tenhamos localizado registros sobre a existência de uma voz de comando dada pelo árbitro de partida daquela época, os fios eram por ele puxados, sendo que as estacas caiam ao mesmo tempo, fazendo com que todos os corredores largassem juntos, como mostra a figura 3.

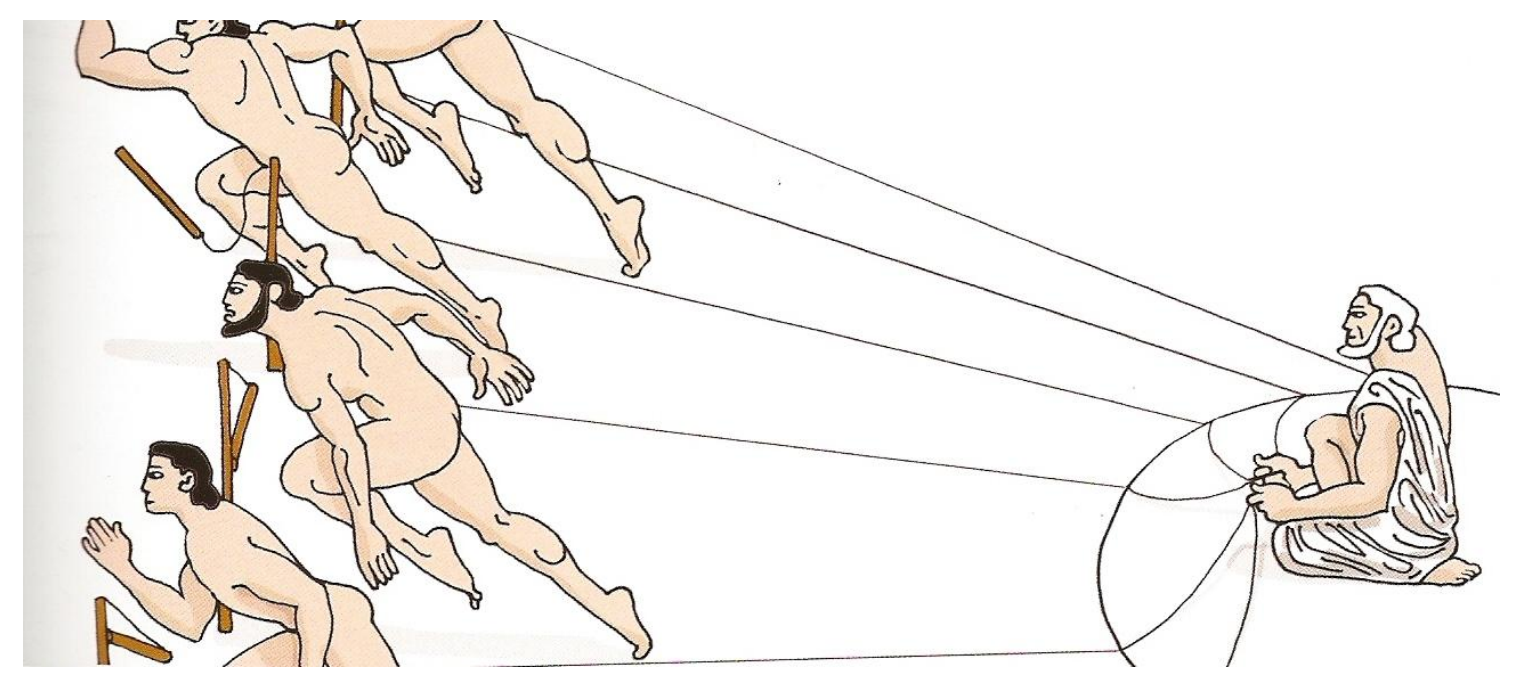

Figura 3- Partida no santuário de Posídon, no Istmo (ANDRONICOS et al, 2004, p.179).

Esse antigo e complexo sistema de largada ficou registrado na história das corridas de velocidade da Grécia Antiga, já que a prova do stádion deixou de ser disputada, sobretudo em função do domínio romano, que levou à interrupção dos Jogos Olímpicos em 369 d. C.

Mesmo assim, algumas competições de corrida de velocidade foram, a exemplo das provas de 100 jardas, disputadas em finais do século XIX. Exemplo disso, é a prova em que ocorreu a primeira saída baixa registrada na história das corridas de velocidade. Denominada como "partida americana", essa saída baixa foi, segundo Kring (1968), utilizada pela primeira vez por Charles H. Sherril, durante os Jogos de Rockaway Hunt Club, em 12 de maio de 1888.

Reforçando ter sido essa a primeira vez na história das corridas de velocidade que um atleta fez aquilo que hoje conhecemos como uma saída baixa, Juncosa Gual (1971) afirma que: "[...] C. H. Sherril inauguró el 'crouch-start' $\mathrm{O}$ salida agachada" (p.8), em 1888 e por iniciativa do técnico Mike Murphy, complementa Silva (1959).

Com o retorno das disputas dos Jogos Olímpicos na Era Moderna, isto é, a partir de 1896, as corridas de velocidade também voltaram a ser disputadas, integrando a programação oficial do atletismo desde essa primeira edição em Atenas.

Disputada apenas por homens, a corrida de velocidade foi realizada em uma linha reta de 100 metros, sem regras pré-definidas em relação ao posicionamento da partida. Nesse sentido, a maior parte dos atletas utilizou a partida em pé, com exceção dos norte-americanos que utilizaram a "partida americana", hoje conhecida como saída baixa. $\mathrm{Na}$ figura 4, que ilustra a final dos 100 metros rasos dos Jogos Olímpicos de 1896, notase que o norte-americano Thomas Burke se diferenciou dos demais atletas ao apoiar suas mãos no chão. Enquanto isso, os demais atletas, com exceção do norte-americano, Francis Lane, ao seu lado esquerdo, aguardavam o tiro de partida em pé. Ao que consta, Burke venceu a prova, conquistando a primeira medalha de ouro da história dos 100 metros rasos dos Jogos Olímpicos da Era Moderna, enquanto Lane, que executou a partida apoiando-se em duas pequenas estacas (FERNÁNDEZ ALBUÍN, 2005), cruzou a linha de chegada em quarto lugar (LANCELLOTTI, 1996). 


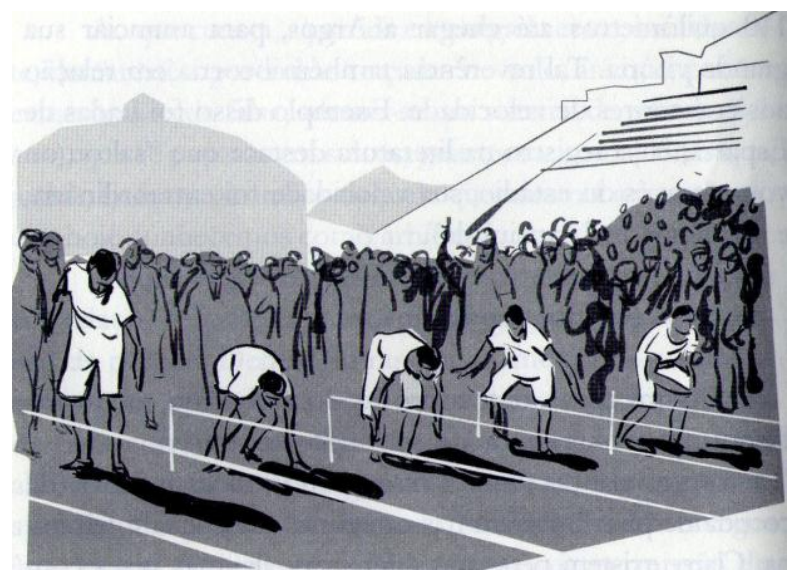

Figura 4- Primeira saída baixa registrada nos Jogos Olímpicos da Era Moderna (MATTHIESEN, 2007, p. 88)

Também há de se reforçar que, a princípio, a saída baixa era realizada sem o bloco de partida, hoje obrigatório em competições oficiais de corridas até e inclusive 400 metros. Ou seja, até 1937 os corredores largavam abaixados, apoiando os pés em pequenos buracos adaptados para a partida (figura 5).

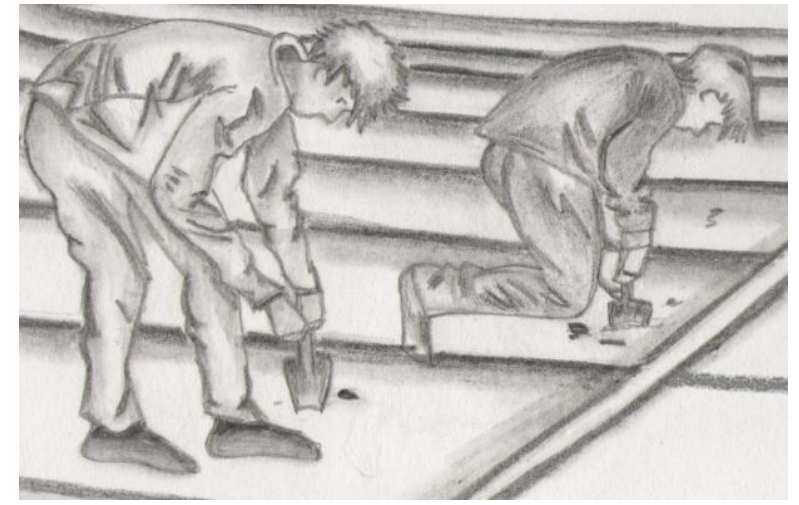

Figura 5- Atletas fazendo suas marcas ("buracos") de partida

Entretanto, além de danificar a pista esse sistema apresentava inconvenientes já que nem sempre os buracos entre os pés dos competidores coincidiam. Apesar de reconhecer que para "uma arrancada mais veloz, é necessário que o atleta tenha um ponto de apoio para os pés", Silva (1959) observa que o "sistema de apoiar os pés em covas de partida" fazia com que, em função das diferenças do "estilo de saída entre um corredor e outro", cada corredor fizesse "pessoalmente a cova de apoio" (p. 30).

Não há dúvidas de que o bloco de partida solucionou o problema dos buracos na pista já que passaram a ser fixados no solo momentos antes da prova, ajustados de corredor para corredor e retirados sem danos. Entre os primeiros blocos de partida existentes estão os de madeira com apoio dos pés separados (figura 6), os de madeira com apoio de metal (figura 7), os em formato em "T" (figura 8) e os de metal (figura 9).

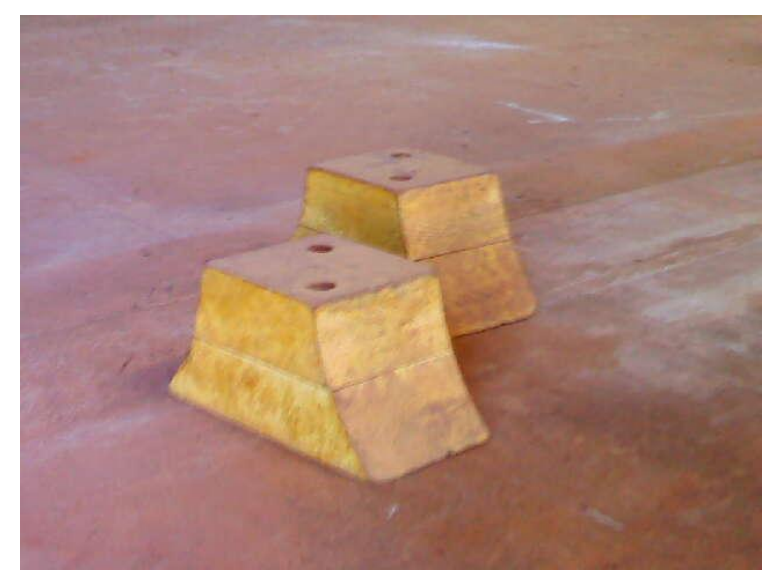

Figura 6- Bloco de partida de madeira com apoio dos pés separados (Fonte: Própria).

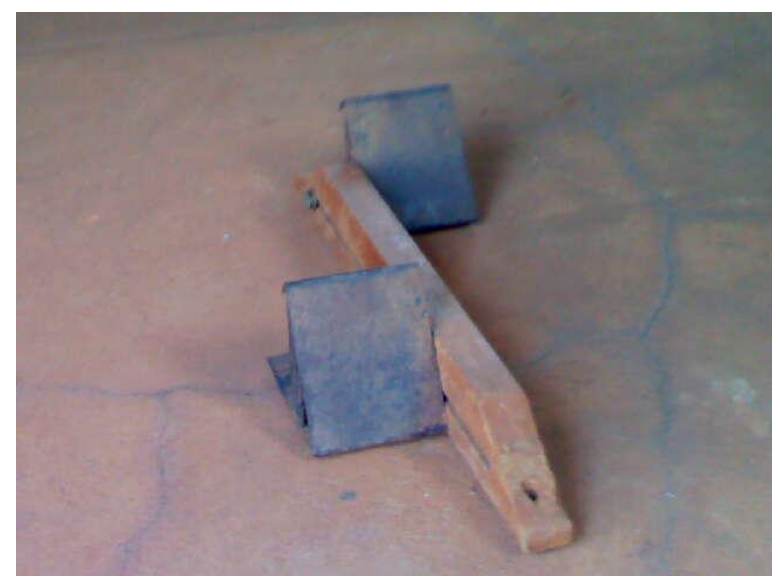

Figura 7- Bloco de partida de madeira com apoio de metal (Fonte: Própria)

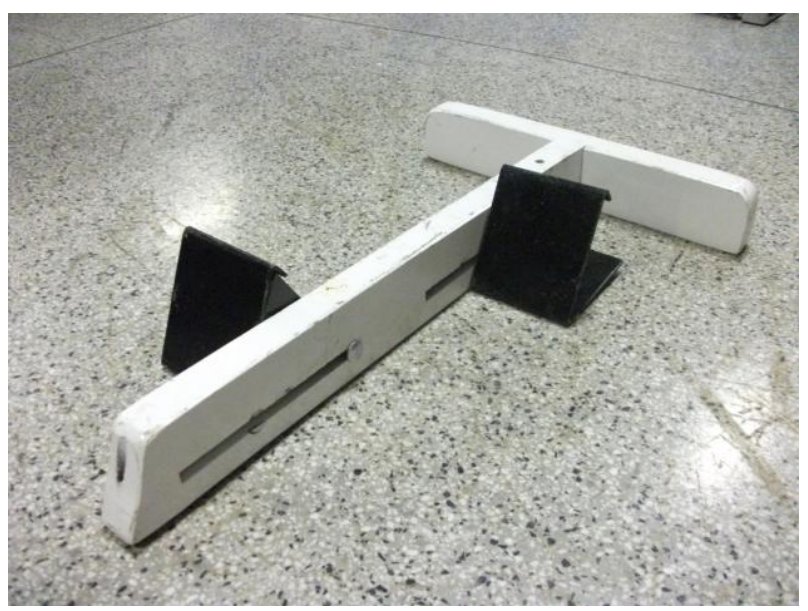

Figura 8- Bloco de partida em "T" (Fonte: Própria)

\footnotetext{
${ }^{1}$ Desenho realizado por: Thaís Yuri Jo Santos.
} 
O fato é que o bloco de partida foi inventado

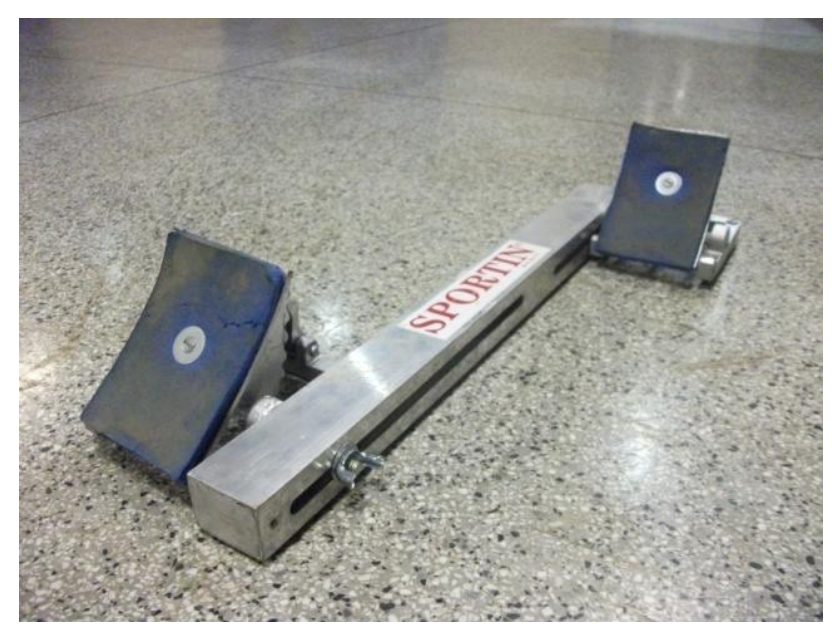

Figura 9- Bloco de partida de metal (Fonte: Própria)

Atualmente, os blocos de partida utilizados em competições oficiais assemelham-se aos da figura 8 , sendo comum um sistema de regulagem para atender às necessidades de cada atleta.

Mas, se essas são algumas das adequações que ocorreram no bloco de partida, facilitando o ajuste e a projeção dos atletas durante a partida das corridas de velocidade, vale observarmos que nem sempre foram obrigatórios em competições. Uma das primeiras referências da utilização do bloco de partida é do Campeonato Universitário da NCAA (National Collegiate Athletic Association), em Chicago, em 1929, ocasião em que o americano George Simpson venceu a prova de 100 jardas (aproximadamente 91,44 metros) usando um bloco de partida, descreve Pallica (1996). Entretanto, ressalta Fernández Abuín (2005), esse tempo não foi homologado, pois "la I.A.A.F., constituida en 1913 no homologa la marca por no estar legalizados los tacos".

Para Berenguer (1970), entretanto, o bloco de partida foi utilizado um pouco antes disso, ou seja: "[...] desde 1927, año em que fueron adoptados por primera vez, los tacos de salida son de adopción general" (p.38). Aprofundando nessa particularidade, identificamos que:

O sistema de tacos de saída foi inventado e patenteado por George T. Bresnahan, em 1927, isto por que havia necessidade de um ponto de apôio para os corredores em locais fechados, como o Madison Square Garden e outros. Com o tempo tais tacos foram aplicados com evidentes vantagens nas pistas externas. Observações feitas comprovaram que os tacos de saídas dão uma vantagem de 30 centímetros, no impulso da partida, sobre as covas preparadas no terreno da pista ( $\underline{\text { Silva, }}$ 1959, p. 30). em 1927 e, como demonstra o site de patentes dos Estados Unidos da América (FREE PATENTS ONLINE, 2009), patenteado por George T. Bresnahan, apenas em 5 de fevereiro de 1929.

Apesar disso, registros fotográficos demonstram que a prova dos 100 metros rasos ocorreu sem o bloco durante os Jogos Olímpicos de Berlim, em 1936 (GINCIENE, 2009).

Um ano depois, em 1937, o bloco de partida passou a ser obrigatório em corridas de velocidade, como descreve Vieira (2007):

\begin{abstract}
Os blocos de partida, nos quais os corredores se apóiam na hora da largada, são de uso obrigatório (desde 1937) em corridas de tiro rápido, como as de $100 \mathrm{~m}, 200 \mathrm{~m}$ e $400 \mathrm{~m}$ (masculino e feminino), e também em provas de revezamento, como $4 \times 100 \mathrm{~m}$ e $4 \times 400 \mathrm{~m}$ (masculino e feminino). Também são utilizadas nas provas de barreiras $100 \mathrm{~m}$ feminino, $110 \mathrm{~m}$ masculino e $400 \mathrm{~m}$ masculino e feminino. Nas demais corridas não são utilizados (p. 31).
\end{abstract}

Em Jogos Olímpicos, o bloco de partida passou a ser utilizado apenas a partir de 1948, quando de sua realização em Londres, já que as edições de 1940 e 1944 não ocorreram devido à $2^{\mathrm{a}}$ Guerra Mundial.

É curioso observar que apesar do bloco de partida ter se tornado obrigatório por regra, tal obrigatoriedade não ocorreu de imediato em relação à saída baixa. Com base nos registros fotográficos encontrados em Pallicca (1996), nas páginas 22 e 35, identificamos duas situações que reforçam esse aspecto. Na primeira, a italiana Antonella Battaglia executa uma partida em pé com o bloco de partida e na segunda, o russo Valery Borzov executa uma partida com 3 apoios (dois pés e a mão direita) numa prova de 100 metros rasos, no Campeonato Europeu de Atletismo de 1974, realizado em Roma (PALLICCA, 1996).

Também em relação ao sistema de partida das corridas de velocidade vale registrar que, atualmente, são três os comandos dados pelo árbitro de partida, quais sejam: "às suas marcas", "prontos" e o tiro de largada. Em todas as corridas de velocidade o atleta deverá, segundo as regras atuais, sair de "uma posição agachada", sendo que "após o comando 'Às suas marcas' [...] Ambas as mãos e um joelho devem estar em contato com o solo e ambos os pés em contato com os blocos de partida." (CBAt, 2003, p.100). Ao sinal de "prontos", o atleta deve "se levantar 
para sua posição final de largada, retendo contato das mãos com o solo e dos pés com o bloco" (CBAt, 2003, p.100). Vale observar que, segundo essa regra, Valery Borzov não poderia executar a saída em três apoios, já que deveria estar com as mãos no solo após o comando de "prontos". Entretanto, no texto da regra daquela época vemos que: "Ao comando de Pronto, todos os competidores deverão, a um só tempo e sem demora, tomar completa e final posição de partida" ( $\mathrm{CBD}, 1973$, p. 58). Ou seja, não há registro de que os atletas naquela época, após a posição final, deveriam estar "retendo contato das mãos com o solo e dos pés com o bloco" (CBAt, 2003, p.100). Com isso, percebemos que não havia nada que determinasse a obrigatoriedade do apoio das mãos no solo, como acontece na regra atual, de forma que ainda era possível realizar a saída baixa sem que as duas mãos estivessem em contato com o solo.

Após esses dois comandos - "às suas marcas" e "prontos" -, é dado o tiro de largada e iniciada a corrida.

Bastante comum em corridas de velocidade, a saída falsa também sofreu várias modificações ao longo dos tempos. Andronicos et al (2004) enfatizam, por exemplo, que 0 atleta que realizasse uma saída falsa na Grécia Antiga "era submetido a um castigo, aparentemente de natureza corporal" (p. 180). Mais tarde, nos Jogos Olímpicos de St, Louis, em 1904, "o atleta que queimasse a largada era punido com um atraso de um metro na linha de saída" (LANCELLOTTI, 1996, p. 33).

Também vale destacar que, até recentemente, permitia-se uma saída falsa por atleta, de modo que se o mesmo atleta cometesse uma segunda infração seria desqualificado. A partir de 01 de janeiro de 2003, apenas uma saída falsa, por prova, passou a ser admitida. Com isso, qualquer atleta que cometesse a segunda saída falsa seria desqualificado. Entretanto, a partir de $1^{\circ}$ janeiro de 2010, qualquer atleta que cometa uma saída falsa estará, automaticamente, desclassificado da prova. Em outras palavras, a saída falsa, por regra, não é mais permitida em corridas de velocidade.

Tais modificações no sistema de partida das corridas de velocidade, certamente, contribuíram para que hoje o recorde mundial masculino, do jamaicano Usain Bolt, seja 9s58, embora alguns, como Martins (2009), ressaltem que ao conquistá- lo, no dia 16 de agosto de 2009, o atleta tenha executado a terceira pior partida da prova, com o tempo de reação de 0s146. Apesar disso, o brilhantismo de seu desempenho durante a prova foi tanto, que superou todas as expectativas melhorando o recorde dele mesmo, de 9s69, conquistado nos Jogos Olímpicos de Pequim, em 2008.

\section{Considerações Finais}

Das várias modificações que ocorreram no sistema de partida das corridas de velocidade desde a corrida do stádion dos Jogos Olímpicos da Grécia Antiga até os atuais 100 metros rasos, talvez, a mais marcante - e que deveria ser abordada pelo professor de Educação Física em suas aulas - seja a obrigatoriedade do bloco de partida.

Embora não seja o único e exclusivo responsável pela melhora dos resultados, é visível e significativa a melhora no tempo da prova dos 100 metros rasos masculino após ter se tornado obrigatório em todas as corridas até e inclusive 400 metros. Vejamos. O recorde mundial masculino demorou 19 anos (1937-1956), após a instauração da regra acerca da obrigatoriedade do bloco de partida, para ser superado. Já no feminino, o recorde mundial foi superado no mesmo ano (1937) em que essa regra foi instaurada, embora não haja registros de que isso tenha ocorrido antes ou depois de sua obrigatoriedade em competições. Contudo, vale observar que se o recorde mundial foi superado antes dessa modificação na regra, a nova recordista teria levado 11 anos (1937-1948) para superar a marca anterior, ao utilizar o bloco de partida, considerando que entre 1939 e 1945, os Jogos Olímpicos não foram realizados em função da $2^{\mathrm{a}}$ Guerra Mundial.

De qualquer forma, é visível a melhora dos tempos no decorrer da história dos 100 metros rasos. Ou seja, foram 113 anos entre o primeiro recorde masculino registrado na história - o recorde olímpico de $11 \mathrm{~s} 8$ de Thomas Burke, nos Jogos Olímpicos de Atenas, em 1896 - e o recorde mundial atual, isto é, os 9s58 de Usain Bolt, conquistado no Campeonato Mundial de 2009, em Berlim.

Durante esse longo período foram várias as modificações que ocorreram na prova, tornandose praticamente inevitável comparamos as condições enfrentadas por ambos os atletas. $\mathrm{Ou}$ seja, enquanto Thomas Burke percorreu os 100 
metros rasos a partir de uma saída baixa que havia sido inventada há apenas 8 anos; sem o bloco de partida; em uma pista e com roupas bem diferentes das utilizadas pelos atletas na atualidade, Usain Bolt, atual recordista mundial, percorreu a mesma distância executando uma saída baixa, a qual foi incessantemente treinada, estudada e analisada; com um bloco de partida; em uma pista sintética; com uma sapatilha personalizada e roupas aderentes ao corpo. Dados os avanços da ciência e da tecnologia, não há como seus tempos não serem tão diferentes!

Isso nos faz refletir sobre os limites dessa prova, isto é, até onde o homem poderá chegar? Será possível melhorar os atuais 9s58 de Usain Bolt? E no feminino, será que alguma mulher irá superar o recorde de 10s49, de Florence Griffith Joyner, que perdura desde 1988? Só o tempo nos dirá.

\section{Referências}

ALBUIN, A. J. P. F. Evolución y análisis de la salida agrupada en la carrera atlética de velocidad. PublicE Standard, Córdoba, abr. 2005.

ANDRONICOS, M. et al. M. Os jogos olímpicos na Grécia antiga. São Paulo: Odysseus, 2004.

BERENGUER, R. Atletismo. Buenos Aires: Stadium, 1970.

\section{CONFEDERACÃO BRASILEIRA DE}

ATLETISMO. Regras oficiais de Atletismo. São

Paulo: Phorte Editora, 2003.

CONFEDERAÇÃO BRASILEIRA DE DESPORTOS. Regras oficiais de Atletismo. [S.I.]: Bloch Editores, 1973.

\section{FAGANELLO, F. R. Análise dos livros de} atletismo como subsídio para o seu ensino no campo escolar. 2008. 167f. Dissertação (Mestrado) - Instituto de Biociências de Rio Claro, Universidade Estadual Paulista, Rio Claro, 2008.

\section{FREE PATENTS ONLINE. All the inventions of} mankind. Disponível em:

$<$ http://www.freepatentsonline.com/1701026.pdf>. Acesso em: 03 jun. 2009.

GINCIENE, G. A evolução histórica da corrida de velocidade: um aprofundamento na prova dos 100 metros rasos. 2009. 192f. Trabalho de Conclusão de Curso (Bacharelado em Educação Física) Instituto de Biociências de Rio Claro, Universidade Estadual Paulista, Rio Claro, 2009.
JUNCOSA GUAL, J. Carreras de velocidad.

Barecelona: Sintes, 1971.

KRING, R. F. Atletismo nas escolas: guia prático de treinamento. São Paulo: Cultura, 1968.

LANCELLOTTI, S. Olimpíada 100 anos. São

Paulo: Círculo do livro, 1996.

MARTINS, J. E. Para técnico, bolt tem largada ruim, mas compensa com explosão. Folha de São Paulo, São Paulo, 17 ago. 2009. Disponível em:

<http://www1.folha.uol.com.br/folha/esporte/ult92u 610550.shtml>. Acesso em: 07 abr. 2010

MATTHIESEN, S. Q. Atletismo: teoria e prática. Rio de Janeiro: Guanabara Koogan, 2007.

MATTHIESEN, S. Q. Sobre o ensino da história do atletismo em aulas de Educação Física. Jundiai: Fontoura, 2010.

PALLICCA, G. Ai vostri posti, pronti, via. AtleticaStudi, Centro Studi \& Ricorche, Roma, n. 34, 1996.

SILVA, N. P. Atletismo. São Paulo: Cia. Brasil, 1959.

VIEIRA, S.; FREITAS, A. O que é atletismo. Rio de Janeiro: Casa da Palavra, 2007.

VIGARELLO, G. Une histoire culturelle du sport: techniques d'hier...et d'aujourd'hui. Paris: Robert Laffont, 1988.

\section{Endereço:}

Guy Ginciene.

Alameda Guarujá, 309. Jardim Paulista.

Vinhedo SP Brasil

13280-000

Cel.: (19) 78104403

e-mail: guy_ginciene@hotmail.com

Recebido em: 15 de outubro de 2010. Aceito em: 19 de novembro de 2011.

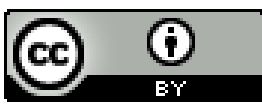

Motriz. Revista de Educação Física. UNESP, Rio Claro, SP, Brasil - elSSN: 1980-6574 - está licenciada sob Creative Commons - Atribuicão 3.0 